\title{
Review and Recommendations of the Neisseria meningitidis Serogroup B Vaccine
}

Tammy Fumiko Messias Takara ${ }^{1^{*}}$ and Maria Joao Esteves ${ }^{2}$

${ }^{1}$ Santa Casa of São Paulo - School of Medicine, Brazil

${ }^{2}$ Porto University, Portugal

"Corresponding author: Takara TFM, General and Family Medicine Department, Porto University, School of Medicine (FMUP), Portugal, Tel: +5511975342634; E-mail: tammymessias@gmail.com

Rec date: Jan 11, 2015 Acc date: April 29, 2015 Pub date: May 05, 2015

Copyright: (C) 2015 Takara TFM, et al. This is an open-access article distributed under the terms of the Creative Commons Attribution License, which permits unrestricted use, distribution, and reproduction in any medium, provided the original author and source are credited.

\begin{abstract}
Background: Meningococcal disease (MD) has high incidence in children less than four years followed by teenagers and Young adults, with high mortality and comorbidities.
\end{abstract}

Objectives: To review the recommendations of Neisseria meningitidis Serogroup B Vaccine around the world. Methods: Medical Literature non sitematic review in English and Portugues Languague in the last 20 years with the following MesH terms "Neisseria meningitidis Serogroup B Vaccine".

Results: 16 papers were full read, of 20 selected. Article's origins of some recognized international relevant institutions like FDA, CDC and $\mathrm{WHO}$. There is a consensus regarding the immunological security $4 \mathrm{CMenB}$ vaccine $\left(\right.$ Bexero $\left.^{\circledR}\right)$.

Discussion: The lack of knowledge of serogroup B strains circulating in Portugal and epidemiological data limits a real estimate to this situation in this country and is not possible to evaluate its benefit cost. European countries are in the middle and low ranges incidence of this MD.

Conclusion: There is no consensus in different countries with similar epidemiology between each other and so with Portugal, on the cost-effectiveness relationship of introducing the vaccine for public funding. The specific studies in each region to evaluate the cost-effectiveness of the vaccine are necessary. Despite the lack of scientific evidence about the cost-effectiveness of vaccination, it is the only current way of prevention MD of serogroup B.

Keywords: Meningococcal disease; Neisseria meningitidis, Serogroup; B Vaccine

\section{Introduction}

Meningococcal disease (MD) is a bacterial infection caused by Neisseria meningitidis, manifested mostly in its most severe form by septicemia (meningococcemia) and/or meningitis. It is globally distributed and can occur in as outbreaks or epidemics, being more frequent in winter (temperate region) and dry seasons (at tropics regions) [1].

The MD has high incidence in children under four years, followed by teenagers and young adults, with high mortality rate ranging from 15 to $30 \%$ for acute meningococcemias and $10-30 \%$ of comorbidities, such as deafness, motor problems, hydrocephalus, mental retardation, cognitive and behavioural problems, thus being considered a serious problem of global public health $[2,3]$.

Neisseria meningitidis is gram-negative diplococci that are classified in to serogroups according to the polysaccharide antigen capsula. There are 13 different serogroups described in the medical literature and the most common serogroups are A,B,C,Y, W135 and X [4].
Humans are the only known natural host and can be asymptomatic carriers of these bacteria in 5-10\% of adults [4]. Transmission occurs from person to person through droplets of nasopharyngeal secretions, and its incubation period is from 3 to 4 days (average) but may vary from two to ten days. Vaccination is the only effective way of prevention the meningococcal disease $[3,4]$.

Serogroups A, B and C are responsible for almost all cases of MD all around the world. In Africa and Asia the most frequents are serogroups $\mathrm{A}$ and $\mathrm{C}$, and serogroups $\mathrm{B}$ and $\mathrm{C}$ are more prevalent on Americas and Europe. In the United States the MD incidence is 0.35 cases per 100 thousand habitants and in Europe is $1.01[1,3]$.

Portugal, in 2011, noticed an MD incidence rate 0.8 per 100 thousand habitants, confirming a declining rate since 2003, due to the decrease of the modality caused by serogroup C, after the introduction of the MenC vaccine in year of 2002 at the privet health system and in 2006 by the National Immunization Program (NIP) at the Public Health System [2].

However, also in the year of 2006 it was observed a higher frequency of the serogroup B (72\%), and a significant increase in the proportion of $\mathrm{Y}$ type group, which rase from 1.7\% (2002-2010) to $14.5 \%$ (2011) [2]. 
There are variability of vaccines that act in the defense related to $\mathrm{MD}$, and currently is used a few different types of vaccines all around the world. Europe has adopted only one of those, the 4CMenB (Bexero $)^{\circ}$, that is derived from bacterial proteins that stimulates the human immune system $[2,3,5]$.

This short communication review aims to evaluate the recommendations of various scientific societies all over the world about the vaccine of the meningococcus serogroup $B$.

\section{Methods}

A search was performed in a non-systematic review of PubMed (MEDLINE), LILACS, Cochrane, and Scopus SCIELO, with the following MesH terms and free text words "meningococcus serogroup B, Meningococcal disease, Neisseria meningitidis and meningococcus vaccine", Articles in English, Spanish and ortuguese languages related to MD, from January 1996 to December 2014, were included. Two authors were responsible for selecting the articles. All abstracts were read and, based on their data, the reviews articles were completely read and detailed.

Those articles covering the meningococcus serogroup B issue vaccines and reviews related to the vaccine were joined to the articles completely read. The inclusion of articles in the review was reviewed by both authors.

Statistical analysis was performed to compare groups using the Sigma XL software, version 6.22.

The study was approved by the Institutional Research Ethics Committee.

\section{Results}

35 papers were selected after the medical research and 20 of them were full read, however, only 16 were included in this revision. All articles were publish after 2010 year and were in English language.

Some of those articles were from recognized institutions worldwide as the World Health Organization, the FDA, CDC and others. The remaining articles were mostly of multidisciplinary groups and especially from countries like Canada, UK, USA, Germany, Brazil, Portugal and China. In general, all authors agree that MD serogroup B is a disease with high morbidity and mortality and its control and treatment are essential. However, the use of $4 \mathrm{CMenB}$ (Bexero ${ }^{\circ}$ ) is no consensus for widespread use in immunization programs.

\section{Discussion}

The first vaccine approved by the European Medicines Agency (EMA), developed by Novartis, has some protein most common circulating strains and potentially immunogenic, that expression on the bacterial surface [5]. Due to the high genetic variability of meningococcus $\mathrm{B}$, was created a mathematical calculation Meningococcal Antigen Typing System (MATS) to estimate the percentage of circulating strains in a certain region [6].

The European average, the accounts showed a $78 \%$ coverage of the strains, but Portugal has not been evaluated in this calculation [7]. The lack of knowledge of serogroup B strains circulating in Portugal and epidemiological data limits a real estimate to this situation in this country and is not possible to evaluate its benefit cost.
Several clinical trials was held in children older than two months, teenagers and adults and in all age groups the vaccine proved to be immunogenic, safe and able to induce immunogenic memory, but this memory is not well defined [5-10]. The most common adverse effects of the vaccine are those related to the injection site, followed by nausea, headache, and fever with short and spontaneous cure.

Serious side effects are rare. The administration of the vaccine in parallel with the National Vaccine Plan (PNV) showed increased local and systemic reactivity, but without major repercussions, with adequate compatibility of administration this vaccine with other vaccines of the calendar $[5,8,9,11]$. There are still no consensuses about the cost benefit rate of the vaccine all over the medical literature. There are an English and a German studies who conclude, through mathematical models, the effectiveness of vaccination. But both emphasize the need to have a similar epidemiology in those countries for their conclusions $[12,13]$.

Already a Canadian study, estimates that spending on a vaccination program significantly exceed the cost thresholds benefit for public funding in the country and do not support this vaccine on their national calendar plan [14].

A systematic review evaluated the current global epidemiology of meningococcal disease in high (10/100 thousand inhabitants year), medium (2-10/100,000 inhabitants year) and low $(<2 / 100$ thousand year) endemicity. In the study, we recommend the use of vaccines against MD only in high and medium impact areas [1].

European countries are in the middle and low ranges incidence of this disease. Countries like Spain, Portugal, Norway, Australia, and the UK have variations in the periods evaluated in the study that after the introduction of MenC, went from average incidence for low. Already Germany, Poland and Canada have remained low endemic countries $[1,15]$.

The vaccine is approved in several countries such as Canada, Australia and other important communities and is also approved by FDA (Food and Drug Administration - USA) and EMA [8,9]. Some scientific societies recommend vaccination, such as the UK, Germany, Poland, Republic Czech and part of Italy [12-14].

It is noted in several studies the difficulty of establishing a good relationship the about cost benefit of this vaccine. Currently, the evidence-based medicine is widely used, but it is clear the methodologicals difficulties in obtaining statistical data in some medical situations, both the ethical aspects involved in research as an appropriate methodology that would be difficult to implement.

Therefore, it has to be pointed out that the lack of scientific evidence does not result in negative evidence. This relationship is important in the evaluation and review of various medical situations of benefit cost relationship.

\section{Conclusions}

All of the studies evaluated in this review conclude that the vaccine against serogroup B meningococcus in the age groups studied infants, children, adolescents and adults, is safe and has few side effects, and most of them are of low gravity.

There are no consensuses in different countries with similar epidemiology between each other and so with Portugal, on the costeffectiveness relationship of introducing the vaccine for public funding. The specific studies in each region to better evaluate the cost- 
Citation: Takara TFM, Esteves MJ (2015) Review and Recommendations of the Neisseria meningitidis Serogroup B Vaccine. Gen Med (Los Angel) 3: 182. doi:10.4172/2327-5146.1000182

Page 3 of 3

effectiveness of the vaccine are necessary. Despite the lack of scientific evidence about the cost-effectiveness of vaccination, it is the only current way of prevention MD of serogroup B.

\section{References}

1. Jafri RZ, Ali A, Messonnier NE, Tevi-Benissan C, Durrheim D (2013) Global epidemiology of invasive meningococcal disease. Popul Health Metr 10: 11-17.

2. Simões MJ, Betencourt C, Cristóvão P (2013) PORTUGAL. Ministério da Saúde. Instituto Nacional de Saúde Doutor Ricardo Jorge, IP. Doença meningocócica invasiva em Portugal. Vigilância epidemiológica de base laboratorial: relatório anual da Rede de Laboratórios Vigilância Lab Doença Meningocócica 2011/- Lisboa: Instituto Nacional de Saúde Doutor Ricardo Jorge, IP 29: 1.

3. Sabatini C, Bosis SC, Semino M, Senatore L, Principi N (2012) Clinical presentation of meningococcal disease in childhood. J prev med hyg 53: 116-119.

4. Brasil (2010) Ministério da Saúde. Secretaria de Vigilância em Saúde. Departamento de Vigilância Epidemiológica. Doenças infecciosas e parasitárias: guia de bolso/Ministério da Saúde, Secretaria de Vigilância em Saúde, Departamento de Vigilância Epidemiológica. 8. ed. rev. Brasília : Ministério da Saúde 444

5. Kaaijk P, van der Ende A, Luytjes W (2014) Routine vaccination against MenB. Human Vaccines \& Immunotherapeutics 10: 310-316.

6. John Donnellya J, Duccio Medinia D, Giuseppe Boccadifuocoa G, Biolchia A, Wardb J, et al. (2014) Qualitative and quantitative assessment of meningococcal antigens to evaluate the potential strain coverage of protein-based vacines. PNAS. 107: 19490-19495.
7. Vogel U, Taha MK, Vazquez JA, Findlow J, Claus H, Stefanelli P, Caugant, DA, et al. (2010) Predicted strain coverage of a meningococcal multicomponent vaccine (4CMenB) in Europe: a qualitative and quantitative assessment. Lancet 13: 416-425.

8. First vaccine approved by FDA to prevent serogroup B Meningococcal disease. FDA News Released 2014.

9. Serogroup B Meningococcal Vaccine \& Outbreaks. CDC. 2014; Link acessed in november 25 th

10. Zlotnick GW, Jones TR, Liberator P, Hao L, Harris S, et al. (2014) The Discovery and Development of a Novel Vaccine to Protect against Neisseria meningitidis Serogroup B Disease. Hum Vaccin Immunother 5: e34293.

11. Findlow J (2013) Meningococcal group B vaccines. Hum Vaccin Immunother 9: 1387-1388.

12. Takla A, Ole Wichmanna O, Kocha J, Terhardtb M, Hellenbranda W (2014) Survey of pediatricians in Germany reveals important challenges for possible implementation of meningococcal B vaccination. Vaccine. 32: 6349-6355

13. Christensen H, MHickman M, Edmunds WJ, Trottera CL (2014) Introducing vaccination against serogroup B meningococcal disease: An economic and mathematical modelling study of potential impact. Vaccine 31: 2638-2646.

14. Tu HA, Deeks S, Morris S, Strifler L, Crowcroft N, et al. (2014) Economic Evaluation Of Meningococcal Serogroup B Childhood Vaccination In Ontario, Canada. The 35th Annual Meeting of the Society for Medical Decision Making.

15. Meningococcal vaccines (2014): WHO position paper 86: 521-540. 